\title{
Tetrahedral amorphous carbon films prepared by magnetron sputtering and dc ion plating
}

J. Schwan, S. Ulrich, H. Roth, and H. Ehrhardt

Universität Kaiserslautern, FB Physik, Schrödingerstrasse, D-67663 Kaiserslautern, Germany

S. R. P. Silva and J. Robertson

Engineering Department, Cambridge University, Trumpington Street, Cambridge CB2 1PZ, United Kingdom

R. Samlenski and R. Brenn

Universität Freiburg, Fakultät für Physik, Hermann Herderstrasse 3, 79104 Freiburg, Germany

(Received 9 June 1995; accepted for publication 17 October 1995)

Highly tetrahedral, dense amorphous carbon (ta-C) films have been deposited using rf sputtering of graphite by an unbalanced magnetron with intense dc Ar-ion plating at low temperatures $\left(<70{ }^{\circ} \mathrm{C}\right)$. The ratio of the argon ion flux to neutral carbon flux $\Phi_{i} / \Phi_{n}$ is about 5 . The film density and compressive stress are found to pass through a maximum of $2.7 \mathrm{~g} / \mathrm{cm}^{3}$ and $16 \mathrm{GPa}$, respectively, at an ion plating energy of about $100 \mathrm{eV}$. Experiments with higher ion flux ratios of $\Phi_{i} / \Phi_{n}=10$ show that it is possible to deposit carbon films with densities up to $3.1 \mathrm{~g} / \mathrm{cm}^{3}$ and $s p^{3}$ contents up to $87 \%$. Deposition of ta-C in this experiment when the energetic species is Ar appears to require a minimum stress of $14 \mathrm{GPa}$ to create significant $s p^{3}$ bonding, which contrasts with the continuous increase in $s p^{3}$ content with stress when the energetic species is $\mathrm{C}$ ions themselves. These results are used to discuss possible deposition mechanisms. () 1996 American Institute of Physics.

[S0021-8979(96)01603-0]

\section{INTRODUCTION}

There has been considerable interest in highly $s p^{3}$ bonded, tetrahedral forms of amorphous carbon (ta-C) in recent years due to their remarkable physical properties. ${ }^{1}$ Koskinen, ${ }^{2}$ and Ishikawa, Ogawa, and Takagi, ${ }^{3}$ and Lifshitz et $a l^{4,5}$ have produced ta-C films containing high fractions of $s p^{3}$ bonding using the mass selected ion-beam (MSIB) deposition method. McKenzie, Muller, and Pailthorpe ${ }^{6}$ and Fallon et $a .^{7}$ have also produced highly $s p^{3}$ bonded ta-C films using a plasma beam of $\mathrm{C}^{+}$ions from a filtered cathodic vacuum arc (FCVA). It was found that the properties of ta-C such as density pass through a maximum as a function of $\mathrm{C}^{+}$ ion energy in each process.

The formation of ta-C by MSIB and FCVA has generally been attributed to deposition by an energetic species, $\mathrm{C}^{+}$. It is also possible to produce high-density $a$-C films by other deposition methods using energetic species, ${ }^{8}$ such as ionassisted deposition in which energetic Ar ions bombard thermal $\mathrm{C}$ atoms during the deposition process. Savvides ${ }^{9}$ was able to produce diamondlike carbon by this method using an unbalanced magnetron, although his method of optical analysis is believed to overestimate the $s p^{3}$ content. Cuomo et al. ${ }^{10}$ were able to prepare $a$-C films with densities up to 3 $\mathrm{g} / \mathrm{cm}^{3}$ by dual-ion-beam sputtering onto well-cooled substrates. Andre, Rossi, and Dunlop ${ }^{11}$ prepared diamondlike carbon films with densities up to $2.7 \mathrm{~g} / \mathrm{cm}^{3}$ using a dual-ionbeam system (DIBS) and ion-beam-assisted dc magnetron (IBAM). Kleber et $a l .{ }^{12}$ deposited $a$-C by magnetron sputtering but the films had a density of $2.0 \mathrm{~g} / \mathrm{cm}^{3}$, which is typical of many magnetron sputtered films.

This article demonstrates that it is possible to deposit ta-C without the use of $\mathrm{C}^{+}$ion beams or plasma beams by using magnetron sputtering in the presence of ion plating (MS/IP). A dc-biased, unbalanced rf magnetron sputter source is operated under conditions of intense Ar-ion plating. The advantage of the magnetron sputter source is that this technique is widely established in industry and allows the deposition onto large areas with relatively high deposition rates. The use of a suitable unbalanced magnetic-field configuration places the substrate immersed in the plasma so that the growing film is bombarded by energetic Ar ions from the plasma. This MS/IP technique is quite effective and has been used by Ulrich et al. ${ }^{13}$ to deposit pure $c$-BN films.

The $a$-C films produced by MS/IP are characterized in terms of their density, $s p^{3}$ fraction, and intrinsic stress. The article also discusses possible mechanisms for the deposition of ta-C by ion plating. The data show that the deposition mechanism differs from that when the film grows from energetic $\mathrm{C}^{+}$ions. The growth of ta-C from energetic $\mathrm{C}^{+}$ions is generally believed to be described by the subplantation mechanism in which the $\mathrm{C}$ ions are energetic enough to enter subsurface atomic sites. In MS/IP, the energetic species is the $\mathrm{Ar}^{+}$ion, which acts only to bombard the growing $a$-C film and is not incorporated in the film. Three types of deposition processes may be of importance:

(i) displacement of $\mathrm{C}$ atoms by $\mathrm{Ar}^{+}$ions into subsurface positions (knock-on or indirect subplantation);

(ii) surface densification of the sputtered carbon atoms in the thin film by argon-ion bombardment;

(iii) conversion of $s p^{2}$ to $s p^{3}$ sites by a high local stress, which is generated by the intense argon ion plating.

These three mechanisms are expected to have different process parameters. The subplantation definitely has a threshold energy, namely the displacement energy, which for carbon lies between 25 and $35 \mathrm{eV}$. The densification process should be of importance at low collision energies (few eV) and high ion flux rates $\Phi_{i}$ (compared to the flux rate of 
neutral carbon atoms $\Phi_{n}$ ). The stress-induced phase transition in the $p T$ phase diagram must show a stress threshold.

\section{EXPERIMENT}

The magnetron is described in detail elsewhere. ${ }^{14,15}$ In an unbalanced magnetron, the plasma extends over both the target and the substrate, so that the Ar ions provide both the sputtering flux to the graphite target and the ion plating flux on the growing film. A high flux of neutral $\mathrm{C}$ atoms is achieved by placing the magnets as close as possible to the graphite target. The configuration of the magnets is a critical parameter, as this determines both the neutral carbon flux $\Phi_{n}$ and the Ar-ion flux $\Phi_{i}$, thereby controlling the deposition rate and the ion plating intensity.

The substrates are sputter cleaned before deposition for $15 \mathrm{~min}$ and they are placed at a distance of $60 \mathrm{~mm}$ from the target. All films have been deposited with rf power of $200 \mathrm{~W}$ and $\mathrm{rf}$ frequency of $13.56 \mathrm{MHz}$. The argon pressure is kept constant at $1.4 \times 10^{-3}$ mbar. The substrate temperature remains below $70{ }^{\circ} \mathrm{C}$. The ion energy and ion fluxes are determined by a Faraday cup placed at the substrate position using a retarding field.

The density and $s p^{3}$ content were measured by electronenergy-loss spectroscopy (EELS). The plasmon spectra of the films were recorded on a $25 \mathrm{keV}$ electron loss spectrometer with a typical energy resolution of $0.38 \mathrm{eV}$ and an acceptance angle of $2 \mathrm{mrad}$. The spectra were corrected for the effects of multiple inelastic scattering and of the restricted acceptance angle. The density was deduced from the valence plasmon energy. Further EELS measurements were performed using a Philips CM30 transmission electron microscope (TEM) operated at $100 \mathrm{keV}$. The $s p^{3}$ content was derived from the intensity of the $\pi^{*}$ peak in the C $K$ loss spectrum, measured on a dedicated parallel EELS spectrometer on a TEM.

The stress was derived from the curvature of the Si substrates using Stoney's equation. The thickness of the films is about $100 \mathrm{~nm}$ measured by ellipsometer and profilometer. The argon content was measured by Rutherford backscattering with $\mathrm{He}^{+}$ion energy of $2 \mathrm{MeV}$.

Films for optical gap measurements were prepared on quartz glass substrates, and the bias voltage was applied in the form of a rf self-bias. The Tauc gap was determined from transmission and reflection spectra.

\section{RESULTS AND DISCUSSION}

\section{A. Film properties}

The analysis of the ion energy distribution and ion mass spectra show that the flux at the substrate consists mainly of neutral $\mathrm{C}$ atoms and $\mathrm{Ar}^{+}$ions. ${ }^{14}$ The mass analysis shows that the $\mathrm{C}$ ion flux is only about $1 \%$ of the $\mathrm{C}$ atom flux and therefore it does not play a significant role in the deposition process.

The energy $E_{n}$ of the neutral $\mathrm{C}$ atoms results from the energy distribution of the sputter process and amounts to a few $\mathrm{eV} .{ }^{15}$ The energy of the Ar ions for zero bias voltage is given by the plasma potential of $24.2 \mathrm{eV}$ and it has a rather sharp energy distribution of $7 \mathrm{eV}$. With additional bias the



FIG. 1. Stress as a function of argon-ion plating energy for carbon films deposited at a $\Phi_{i} / \Phi_{n}$ ratio of 5.4.

width of the energy distribution remains constant. The ratio $\Phi$ of the argon ion flux $\Phi_{i}$ to carbon neutral flux $\Phi_{n}$ is found to be 5.4. This means that on average each carbon atom is hit by about five argon ions while it rests on the film surface. The product $E_{n} \Phi_{n}$ is much smaller than $E_{i} \Phi_{i}$ of the argon ions and can be neglected in the energy balance during film formation.

The $\mathrm{C}$ atom flux was derived from the mass deposition rate. The deposition rate is $0.43 \AA / \mathrm{s}$ at an argon-ion energy of $24.2 \mathrm{eV}$ and decreases to $0.27 \AA / \mathrm{s}$ for an Ar-ion energy of $130 \mathrm{eV}$. Since $\Phi_{n}$ and $E_{n}$ remains constant, the reduction in film thickness with increasing ion plating energy results partly from the densification of the material and partly from resputtering of the deposited carbon film.

Figure 1 shows the variation of the intrinsic stress of the $a-\mathrm{C}$ films as a function of $\mathrm{Ar}^{+}$-ion energy for an ion flux ratio of $\Phi=5.4$. For each Ar plating energy the stress has been measured for five times always showing the same behavior. Here the medium stress of those measurements is plotted in Fig. 1. The stress is compressive, and it is intrinsic because the films are deposited at room temperature, so there is no component due to the thermal expansion coefficients. The stress is seen to increase gradually and to pass through a maximum of $16 \mathrm{GPa}$ at an $\mathrm{Ar}^{+}$energy of $100 \mathrm{eV}$ before decreasing again at higher $\mathrm{Ar}^{+}$energies. The compressive stress variation is found to be more sharply peaked at a flux $\Phi$ of 10 , reaching a value of $19 \mathrm{GPa}$ at a slightly lower Ar-ion energy of $90 \mathrm{eV}$.

Figures 2 and 3 show the variation of the density and $s p^{3}$ content with $\mathrm{Ar}^{+}$energy for $\Phi=5.4$ and 10 . As the $\mathrm{Ar}^{+}$energy increases, the density is seen to remain at a graphitic value of about $2.0 \mathrm{~g} / \mathrm{cm}^{3}$ up to $70 \mathrm{eV}$ and then to increase sharply to a peak of $2.7 \mathrm{~g} / \mathrm{cm}^{3}$ at around $105 \mathrm{eV}$ for $\Phi=5.4$ and to a peak of $3.1 \mathrm{~g} / \mathrm{cm}^{3}$ at $90 \mathrm{eV}$ for $\Phi=10$. The density then decreases sharply at highly $\mathrm{Ar}^{+}$energies to its graphitic value. The $s p^{3}$ fraction behaves roughly in a similar fashion, staying at quite low $s p^{3}$ values and then increasing sharply for $\mathrm{Ar}^{+}$energies around $80-120 \mathrm{eV}$, before decreasing 


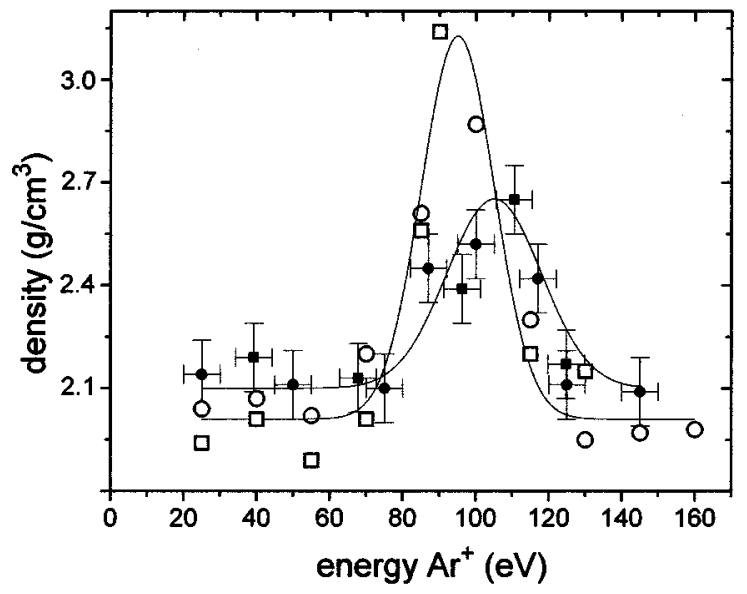

FIG. 2. Density as a function of argon-ion plating energy for films deposited at $\Phi=5.4$ (solid symbols) and $\Phi=10$ (open symbols). Films deposited at the different $\Phi$ ratios were analyzed by EELS electron beams with beam characteristics ( $25 \mathrm{keV}$ and $2 \mathrm{mrad}$ and (ם) $100 \mathrm{keV}$ and $10 \mathrm{mrad}$.

sharply again. The peak value of $s p^{3}$ fraction is $60 \%$ for $\Phi=5.4$ and $87 \%$ for $\Phi=10$.

In order to gain more information about the deposition mechanism, it is instructive to plot the density and $s p^{3}$ fraction against compressive stress, as shown in Figs. 4 and 5. The density variation is seen to lie on the same curve plotted versus stress for both ion flux ratios. The density is seen to remain low until the stress reaches about $13 \mathrm{GPa}$, and then increases strongly with stress. The $s p^{3}$ fraction also varies in a similar fashion with stress, remaining relatively constant and then increasing rapidly once the stress exceeds the threshold of $13 \mathrm{GPa}$. There is a greater scatter for the $s p^{3}$ data; the $s p^{3}$ values at low stress appear slightly higher for $\Phi=10$, but the data tend to lie in the same curve above the threshold.

This variation of density and $s p^{3}$ content with stress is different from that found in ta-C deposited from the FCVA,

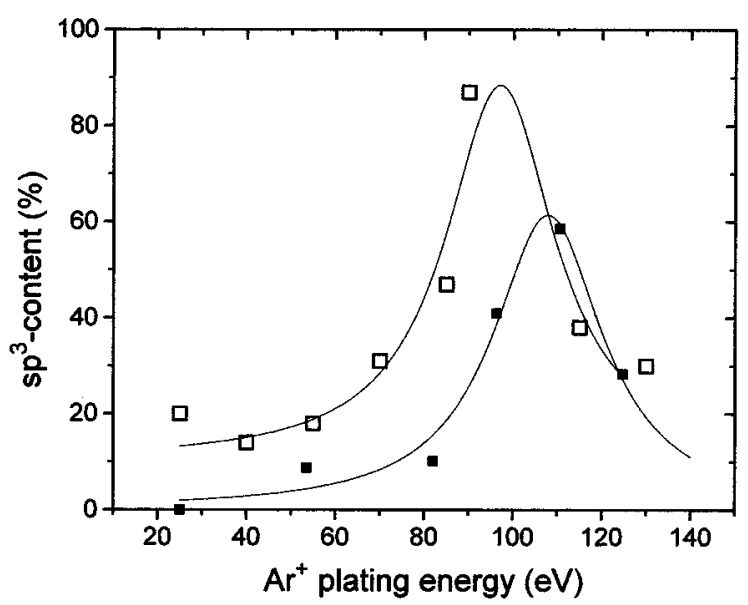

FIG. 3. $s p^{3}$ content as a function of argon-ion plating energy for and $(\square) \Phi=10$.

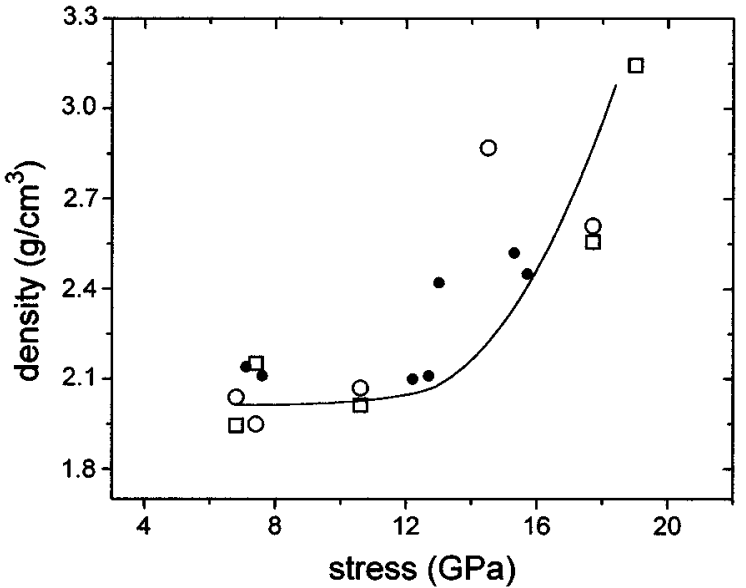

FIG. 4. Density vs stress for carbon films deposited at $(\bullet) \Phi=5.4(25 \mathrm{keV}$, $2 \mathrm{mrad}) ;(\bigcirc) \Phi=5.4$ (25 keV, $2 \mathrm{mrad}) ;(\square) \Phi=10$ (100 keV, $10 \mathrm{mrad}$ ).

where the films are deposited by energetic $\mathrm{C}^{+}$ions themselves, where they are found to vary essentially linearly with stress. ${ }^{6,16}$

Figure 6 shows that the $s p^{3}$ content varies linearly with density. A similar variation was found for ta-C from the FCVA ${ }^{6,16}$ A similar dependence is found because the dependence of density on $s p^{3}$ content is essentially a property of the material. ${ }^{16}$ In contrast, the dependence of density and $s p^{3}$ content on stress is a function of the deposition process itself.

Figure 7 shows the Ar content of the $a$-C films as a function of $\mathrm{Ar}^{+}$energy as determined by Rutherford backscattering spectroscopy (RBS). The Ar content is seen to be quite low, $6 \%$, and to decrease to a value of only $3 \%$ at an $\mathrm{Ar}^{+}$energy of $100 \mathrm{eV}$, where the film density reaches a maximum. This suggests that Ar incorporation is restricted when the ta-C density is high. Further this suggests that the main component of the stress must come from the carbon structure itself.

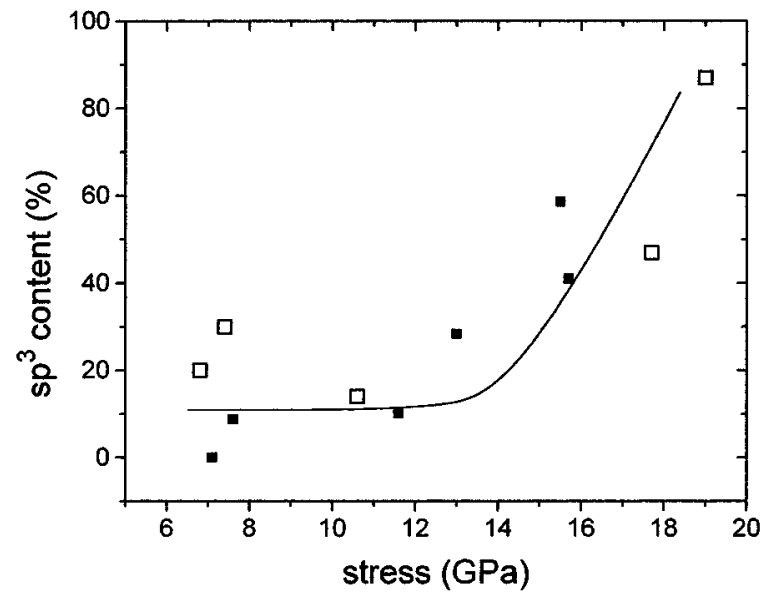

FIG. 5. $s p^{3}$ content vs stress for carbon films deposited at $\Phi=5.4(100$ $\mathrm{keV}, 10 \mathrm{mrad})$ and $(\square) \Phi=10(100 \mathrm{keV}, 10 \mathrm{mrad})$. 


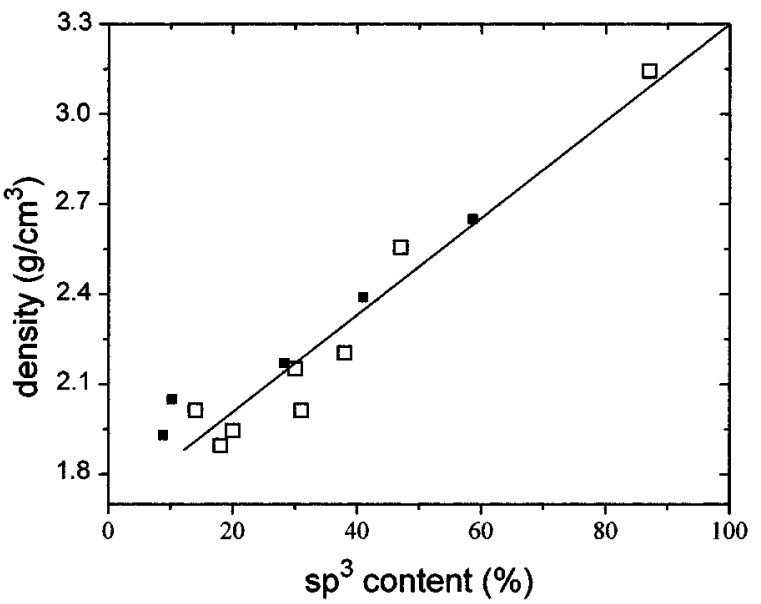

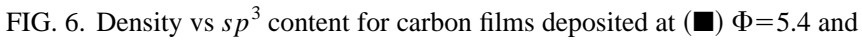
$(\square) \Phi=10$

\section{B. Deposition mechanism}

The creation of $s p^{3}$ sites in ta-C prepared by energetic $\mathrm{C}^{+}$ion deposition is generally believed to arise from subplantation. ${ }^{4,17}$

The ion has sufficient energy to penetrate the surface atomic layer and enter a subsurface atomic site. There are two ways a $\mathrm{C}$ atom could occupy a subsurface site, either by direct penetration [Fig. 8(a)] or by incident ion displacing a surface atom into that site [Fig. 8(b)]. The subplantation also creates a large compressive stress. This process has been analyzed recently, ${ }^{17,18}$ and analytic expressions have been given for the fraction of $s p^{3}$ sites.

MS/IP deposition differs in that energetic $\mathrm{Ar}^{+}$ions can only displace $\mathrm{C}$ atoms from the surface into subsurface sites. This is analogous to the displacement process in Fig. 8(b). Subplantation by both process (a) and (b) requires the ion energy to exceed a threshold, close to the displacement energy of about $25 \mathrm{eV} .{ }^{17}$ The density should then increase gradually above this energy, until it begins to decrease at high ion energies, due to the annealing in a thermal spike.

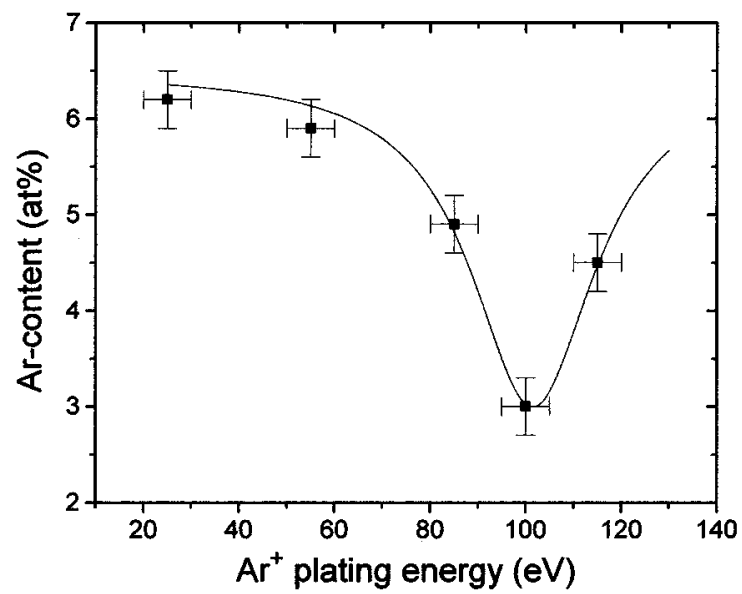

FIG. 7. Argon content as a function of argon-ion plating energy.
a) direct subplantation

b) indirect subplantation (knock on penetration)



FIG. 8. Direct and knock-on (indirect) penetration by ions.

The density and $s p^{3}$ content clearly do not follow this behavior in the MS/IP ta-C. This suggests that the knock-on subplantation, process (b), is not particularly efficient, in that there is little increase in density up to say $60 \mathrm{eV}$. In contrast the compressive stress is found to follow the expected dependence on ion energy. However, this is still not consistent with the original subplantation model in that the stress and density should correlate with each other.

A second possible process is that the Ar-ion bombardment could cause a densification of surface layers by displacing $\mathrm{C}$ atoms inward. In this model the densification and stress formation of the sputtered carbon atoms in the films are due to energy and momentum transfer by low-energy argon-ion plating. The knock-on collisions of the argon ions ensures that void formation is unlikely. This process is expected to be significant because each $\mathrm{C}$ atom is hit by on average five $\mathrm{Ar}^{+}$ions before being covered by the next layer. Densification differs from subplantation in that it does not require a threshold energy. The lack of densification at low energies however suggests that this process is relatively small in MS/IP.

The third possible process is a stress-induced transformation of $s p^{2}$ sites to $s p^{3}$ sites. McKenzie and co-workers ${ }^{6}$ attributed the generation of ta- $\mathrm{C}$ to a quasithermodynamic transition on a pressure/temperature phase diagram. In his model, pressure is generated by the stress in the films whereas temperature is generated by energetic carbon ions impinging on the surface of the carbon film. Takano, Harashima, and Wakatsuki, ${ }^{19}$ Endo et al. ${ }^{20}$ and Yagi et al. ${ }^{21}$ have shock compressed graphite at room temperature. They reported a martensitic (displacive) phase transformation from $s p^{2}$ to $s p^{3}$ bonded carbon at room temperature for pressure values above $15 \mathrm{GPa}$. Scandolo et al. $^{22}$ and Kitabatake ${ }^{23}$ showed by $a b$ initio molecular-dynamic studies a pressureinduced transformation path of graphite to diamond. In the case of MS/IP ta-C we observe that the deposition process has created a very large compressive stress. This stress is larger than that found in ta-C formed by FCVA. Simulations suggest that the stress is not uniform but varies between sites. ${ }^{24}$ Since the $s p^{3}$ content enhances rapidly if the stress exceeds values above $14 \mathrm{GPa}$ (see also Fig. 7), we propose 


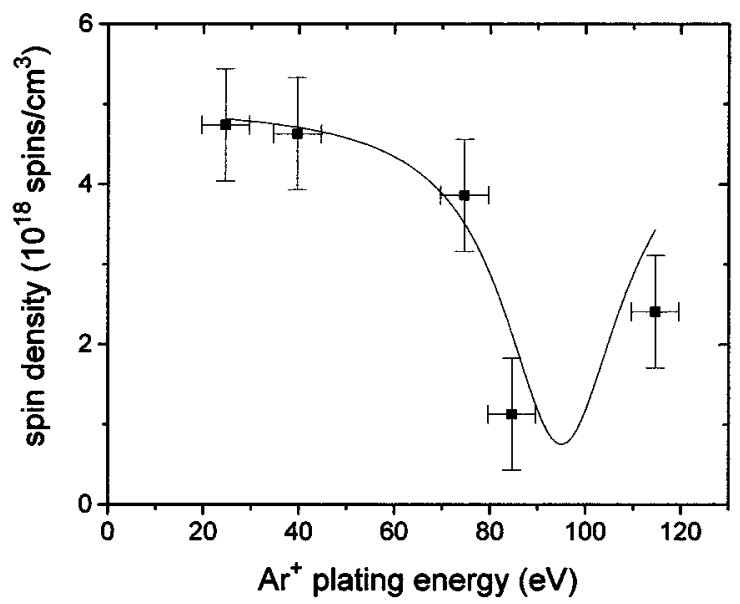

FIG. 9. Spin density as a function of argon-ion plating energy.

that this stress causes pairs of $s p^{2}$ sites to bond together to form $s p^{3}$ sites. The stress in the films induces a phase transformation of $s p^{2}$ to $s p^{3}$ hybridized carbon. The observed threshold stress is large, about $14 \mathrm{GPa}$ from Figs. 4 and 5. This stress is much larger than that given by the BermanSimon line $1.6 \mathrm{GPa}$, which corresponds to the isothermal conversion of graphite to diamond. It seems that stress values above say $4 \mathrm{GPa}$ and below $14 \mathrm{GPa}$ are a necessary condition for the preparation of ta-C films, but they are not a sufficient condition for the preparation of ta-C films.

The different processes can clearly be distinguished by their different threshold energies. In the subplantation model the energy threshold is given by the displacement energy. Densification should occur if ions have a higher energy than the displacement energy. In contrast, there is no threshold in the densification model. The densification by these deposition processes plays a minor role because stress and densification do not correlate with each other and no densification is observed for Ar-ion energies below $60 \mathrm{eV}$.

In the third process, a threshold stress of about $14 \mathrm{GPa}$ exists for the transformation of $s p^{2}$ sites to $s p^{3}$ sites. This is close to the threshold observed for shock-compressed graphite. $^{19-21}$

\section{Electrical properties}

The Tauc gap of each of the films was found to be low, well below $1 \mathrm{eV}$, even in those films containing large $s p^{3}$ contents. The optical gap is controlled by the configuration of the $\pi$ states. $^{25}$ The intense ion bombardment during deposition is likely to produce strong disordering of the $s p^{2}$ sites, and to lower the optical gap. ${ }^{26}$ The lowering of the optical band gap arises from the mixing of $\sigma$ and $\pi$ states.

The density of electronically active defect states can be measured by electron-spin resonance (ESR). Figure 9 shows that the spin density is sizeable in MS/IP $a$-C. The spin density is seen to be a minimum at the $\mathrm{Ar}^{+}$energy of maximum density. The spin density is found to be less than in ta-C prepared by the FCVA, ${ }^{27}$ despite the higher disorder in the present films. This suggests that defect density is not just controlled by the intrinsic disorder.

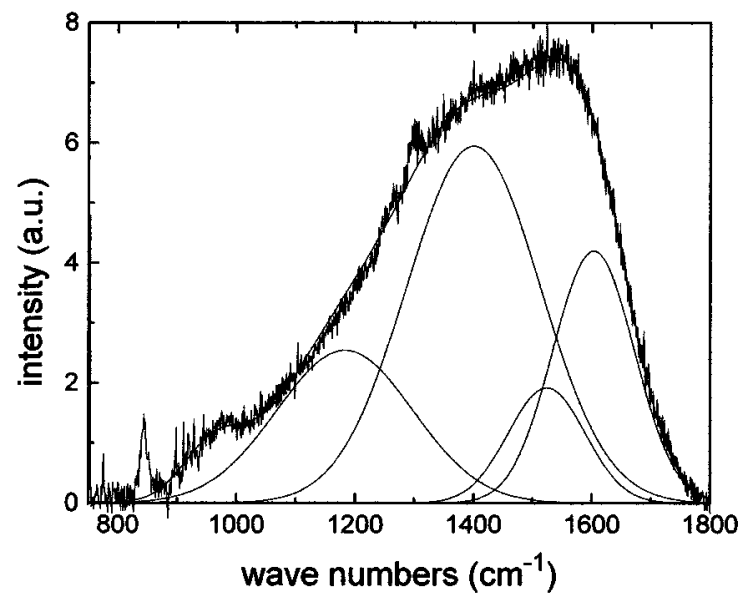

FIG. 10. Raman spectrum of a MS/IP carbon film deposited at an argon plating energy of $110 \mathrm{eV}$.

The width of the ESR line gives information on the nature of the defect state. With ESR a narrow ESR line of about $2.5 \mathrm{G}$ is found for films deposited at all argon plating energies. In $a$-C the spin signal is thought to arise from unsaturated $\pi$ bonds. A narrow ESR line in $a-\mathrm{C}$ is a strong indication that exchange narrowing occurs. A small linewidth of $2.5 \mathrm{G}$ indicates that the $\pi$-spin centers are close together and interact, so that those $s p^{2}$ clusters where the spins are located are not independent from each other and pairing of spins is likely to occur.

The MS/IP $a-\mathrm{C}$ films show a high electrical conductivity $\left(>4 \Omega^{-1} \mathrm{~cm}^{-1}\right)$. This finding can be understood if we assume connected $s p^{2}$ regions. This would also be consistent with the narrow optical gap in these materials. Rossnagel, Russak, and Cuomo ${ }^{28}$ found that magnetron-sputtered $a-\mathrm{C}$ at a pressure of $10^{-3}$ mbar had a conductivity of $1 \Omega^{-1} \mathrm{~cm}^{-1}$, similar to the value found here. The electronic properties are determined by the $s p^{2}$ matrix due to the $\pi$ - $\pi^{*}$ states being closer to the Fermi level. ${ }^{25}$

\section{Raman}

The Raman spectrum of the ta-C film for $\Phi=5.4$ is shown in Fig. 10. Generally speaking, the Raman spectra of nanocrystalline $\mathrm{C}$ are dominated by the features of the $s p^{2}$ component because of its much larger Raman scattering. The Raman spectra are fitted by four Gaussians. The $1600 \mathrm{~cm}^{-1}$ $G$ peak corresponds to the zone center Raman mode of graphite. The $1380 \mathrm{~cm}^{-1} \mathrm{D}$ peak corresponds to the zone boundary mode of graphite which becomes active for finite crystallites. ${ }^{29}$ The origin of the peak at $1480 \mathrm{~cm}^{-1}$ is not clear.

The peak at $1170 \mathrm{~cm}^{-1}$ is not due to a $s p^{2}$ feature. $\mathrm{Ne}$ manich et al. ${ }^{30}$ said that this feature is present in films with small amounts of diamond crystalline domains indicating that it could be a diamond precursor structure. They further suggested that Raman peaks around $1175 \mathrm{~cm}^{-1}$ are due to regions of microcrystalline diamond or amorphous diamond. Silva et $a l .{ }^{31}$ attributed this peak to hexagonal diamond crys- 


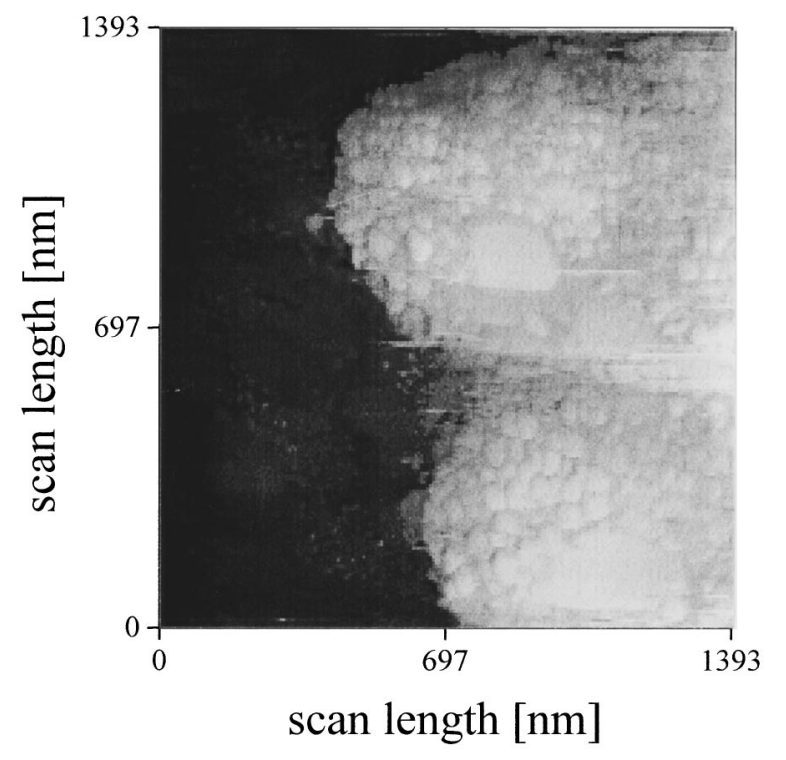

FIG. 11. Atomic force microscopy picture of a MS/IP ta-C film (deposited at $110 \mathrm{eV}$ argon plating energy) after diamond nucleation of $30 \mathrm{~min}$.

tallites within an amorphous carbon matrix. Wagner, Wild, and $\mathrm{Koidl}^{32}$ attributed the $1150 \mathrm{~cm}^{-1}$ peak to nanocrystalline diamond.

The MS/IP deposited films have been exposed to a microwave plasma in a $\mathrm{H}_{2}(99 \%) / \mathrm{CH}_{4}(1 \%)$ mixture, at a substrate temperature $800{ }^{\circ} \mathrm{C}$. These conditions are normally suitable for diamond deposition. The atomic hydrogen in the plasma causes preferential etching of amorphous and graphitic carbon structures. These conditions will even etch ta-C which has been deposited by FCVA or by a plasma beam source. ${ }^{33}$ However, the plasma does not fully etch ta-C deposited by MS/IP. This indicates that the MS/IP deposited films contains $s p^{3}$ nuclei which were not completely etched by atomic hydrogen. The treatment of such films under diamond growing conditions leads to a cauliflower appearance of growth (Fig. 11). Conclusive x-ray diffraction (XRD) measurements for the existence of diamond seeds in the films could not be performed, because the needed film thickness (for XRD) of the carbon films is limited due to the high stress. Synchrotron XRD measurements which can deal with 100 -nm-thick films are in preparation.

Therefore we assume that the structure of the MS/IP deposited carbon films is given by a $s p^{2}$ matrix or net, in which $s p^{3}$ clusters are embedded. It seems that there is some, not yet identified, order in the $s p^{3}$ clusters as indicated from Raman spectra and from the diamond nucleation experiment. Such a cluster structure would explain the electronic properties $\left(s p^{2}\right.$ matrix/net) and the high density. Also stress and $s p^{3}$ content are explained by the existence of such clusters.

The physical properties of the ta- $\mathrm{C}$ films prepared under the MS/IP conditions are completely different to those of the ta-C prepared by the MSIB technique or vacuum arc. Table I shows some physical properties for ta-C prepared by the indirect subplantation process (MS/IP) and direct subplantation process (FCVA). The different physical properties of the ta-C films have their origin in the different microstructures of the materials.
TABLE I. Physical properties of ta-C films prepared by the MS/IP technique and FCVA (Refs. 6, 7, and 35).

\begin{tabular}{|c|c|c|}
\hline & MS/IP & FCVA \\
\hline$s p^{3}$ content & $87 \%$ & $<90 \%{ }^{\mathrm{a}}$ \\
\hline Density & $3.1 \mathrm{~g} / \mathrm{cm}^{3}$ & $\approx 3.1 \mathrm{~g} / \mathrm{cm}^{3} \mathrm{~b}$ \\
\hline Stress & $<19 \mathrm{GPa}$ & $<11 \mathrm{GPa}^{\mathrm{c}}$ \\
\hline Optical gap & $\begin{array}{l}\approx 0 \mathrm{eV} \\
\text { at } \Phi_{i} / \Phi_{n}=5\end{array}$ & $1.5-2.1 \mathrm{eV}^{\mathrm{c}}$ \\
\hline Electrical resistance & $\begin{array}{l}<0.25 \Omega \mathrm{cm} \\
\text { at } \Phi_{1} / \Phi_{n}=5\end{array}$ & $>10^{6} \Omega \mathrm{cm}^{\mathrm{d}}$ \\
\hline Raman & strong $D$ peak & weak $D$ peak $^{\mathrm{b}}$ \\
\hline $\begin{array}{l}{ }^{\mathrm{a}} \text { Reference } 34 . \\
{ }^{\mathrm{b}} \text { Reference } 6 . \\
{ }^{\mathrm{c}} \text { References } 7 \text { and } 34 .\end{array}$ & $\begin{array}{l}{ }^{\mathrm{d}} \text { Reference } 35 . \\
{ }^{\mathrm{b}} \text { Reference } 36 .\end{array}$ & \\
\hline
\end{tabular}

\section{SUMMARY AND CONCLUSION}

Recently, Ulrich et al. ${ }^{13,37}$ have prepared $c$-BN films by rf magnetron sputtering and ion plating with an $c$-BN content of about $93 \%$. In both cases, the $\mathrm{BN}$ and the presently described $\mathrm{C}$ films have high fractions of $s p^{3}$ bondings. These metastable materials have higher densities than their stable $s p^{2}$ modifications, i.e., hexagonal BN and graphite. In both cases it has been shown that low-energy but intense ion bombardment with argon ions the densities of the films can be increased considerably leading to phase transition in both cases to the $s p^{3}$-rich modifications at low temperatures.

Compressive stress in the films arises from ion peening. The compressive stress may be explained in terms of the subplantation model. However, the subplantation model does not explain the energy-dependent sharp maximum in density of the carbon films. Further the lack of densification at low ion energies suggests that (indirect) subplantation process and densification process by argon bombardment have only a small influence on the densification of the $\mathrm{C}$ films.

Stress measurements reveal that $s p^{3}$ bonded carbon is predominantly deposited for stress values above $14 \mathrm{GPa}$. The existence of such a stress threshold proves that in the MS/IP $a-\mathrm{C}$ films exists a stress-induced transformation from $s p^{2} \rightarrow s p^{3}$ bonded sites. The stress threshold for the deposition of dense carbon films is much higher than the BermanSimon line which was proposed by McKenzie and coworkers. ${ }^{6}$

The present results indicate strong clustering of $s p^{3}$ hybridized carbon. Those $s p^{3}$ seeds are responsible for the high density in the carbon films. The electronic properties, such as optical gap and electrical conductivity of the deposited MS/IP carbon films, seem to be predominantly determined by a $s p^{2}$ matrix in which $s p^{3}$ clusters are embedded.

It follows from our experimental results that, quite generally, by low-energy ion plating at low temperatures any metastable material can be produced, if its density is higher than the density of its stable modification. This is of importance for the production of superhard coatings with $\mathrm{C}, \mathrm{B}$, and $\mathrm{N},{ }^{38}$ consisting of covalent bondings.

\section{ACKNOWLEDGMENT}

The authors want to thank Professor Schmoranzer, Physics Department, University of Kaiserslautern, for most valuable support by EELS measurements. 
${ }^{1}$ J. Robertson, Prog. Solid State Chem. 19, 199 (1991).

${ }^{2}$ J. Koskinen, J. Appl. Phys. 63, 2094 (1988).

${ }^{3}$ T. Y. Ishikawa, K. Ogawa, and T. Takagi, J. Appl. Phys. 61, 2509 (1987).

${ }^{4}$ Y. Lifshitz, S. R. Kasi, J. W. Rabalais, and W. Eckstein, Phys. Rev. B 41, 10468 (1990).

${ }^{5}$ Y. Lifshitz, G. D. Lempert, E. Grossmann, I. Avigal, C. Uzan-Saguy, R. Kalish, J. Kulik, D. Marton, and J. W. Rabalais, Diamond Related Mater. 4, 312 (1995)

${ }^{6}$ D. R. McKenzie, D. Muller, and B. A. Pailthorpe, Phys. Rev. Lett. 67, 773 (1991).

${ }^{7}$ P. J. Fallon, V. S. Veerasamy, C. A. Davis, J. Robertson, G. Amaratunga, W. I. Milne, and J. Koskinen, Phys. Rev. B 48, 4777 (1993).

${ }^{8}$ J. J. Cuomo, D. L. Pappas, J. Bruley, J. P. Doyle, and K. L. Saenger, J. Appl. Phys. 70, 1706 (1991).

${ }^{9}$ N. Savvides, J. Appl. Phys. 59, 4133 (1986).

${ }^{10}$ J. J. Cuomo, J. P. Doyle, J. Bruley, and J. C. Liu, Appl. Phys. Lett. 58, 466 (1991).

${ }^{11}$ B. Andre, F. Rossi, and H. Dunlop, Diamond Related Mater. 1, 307 (1992).

${ }^{12}$ R. Kleber, M. Weiler, A. Krüger, S. Sattel, G. Kunz, K. Jung, and H. Ehrhardt, Diamond Related Mater. 2, 246 (1991).

${ }^{13}$ S. Ulrich, J. Scherer, J. Schwan, I. Barzen, K. Jung, and H. Ehrhardt, Diamond Related Mater. 4, 288 (1995).

${ }^{14}$ W. Dötter, I. Barzen, R. Erz, S. Ulrich, K. Jung, and H. Ehrhardt, Fresenius J. Anal. Chem. 1991, 341.

${ }^{15}$ H. Ehrhardt, S. Ulrich, I. Barzen, J. Scherer, and K. Jung, Mater. Wiss. u. Werkstofftech. 24, 74 (1993).

${ }^{16}$ J. Robertson, Pure Appl. Chem. 66, 1789 (1994).

${ }^{17}$ J. Robertson, Diamond Related Mater. 2, 984 (1993); 3, 361 (1994).

${ }^{18}$ C. A. Davis, Thin Solid Films 30, 276 (1993).

${ }^{19}$ K. J. Takano, H. Harashima, and M. Wakatsuki, Jpn. J. Appl. Phys. 30, L860 (1991).

${ }^{20}$ S. Endo, N. Idani, R. Oshima, K. J. Takano, and M. Wakatsuki, Phys. Rev. B 49, 22 (1994).
${ }^{21}$ T. Yagi, W. Utsumi, M. Yamakata, T. Kigegawa, and O. Shimomura, Phys. Rev. B 6, 6031 (1992).

${ }^{22}$ S. Scandolo, M. Bernasconi, G. L. Chiarotti, P. Focher, and P. Tosatti, Phys. Rev. Lett. 74, 4015 (1995).

${ }^{23}$ M. Kitabatake, Diamond Films Technol. 5, 41 (1995).

${ }^{24}$ P. C. Kelires, Phys. Rev. Lett. 73, 2460 (1994).

${ }^{25}$ J. Robertson and E. P. O'Reilly, Phys. Rev. B 35, 2946 (1987).

${ }^{26}$ J. Robertson, Diamond Related Mater. 4, 297 (1995).

${ }^{27}$ G. Amaratunga, J. Robertson, V. S. Veerasamy, W. I. Milne, and D. R. McKenzie, Diamond Related Mater. 4, 637 (1995).

${ }^{28}$ S. M. Rossnagel, M. A. Russak, and J. J. Cuomo, J. Vac. Sci. Technol. A 5, 2150 (1987).

${ }^{29}$ P. Koidl, C. Wild, B. Dischler, J. Wagner, and M. Ramsteiner, J. Mater. Sci. 52, 41 (1990).

${ }^{30}$ R. J. Nemanich, T. J. Glass, G. Lucovsky, and R. E. Shroder, J. Vac. Sci. Technol. A 6, 1783 (1988).

${ }^{31}$ S. R. P. Silva, G. A. J. Amaratunga, E. K. Salja, and K. M. Knowles, J. Mater. Sci. 29, 4962 (1994)

${ }^{32}$ J. Wagner, C. Wild, and P. Koidl, Appl. Phys. Lett. 59, 779 (1991).

${ }^{33}$ S. Sattel, M. Weiler, J. Gerber, T. Giessen, H. Roth, M. Scheib, K. Jung, H. Ehrhardt, and J. Robertson, Diamond Related Mater. 4, 333 (1995).

${ }^{34}$ P. H. Gaskell, A. Saeed, P. Chieux, and D. R. McKenzie, Phys. Rev. Lett. 67, 1286 (1991).

${ }^{35}$ V. S. Veerasamy, G. A. J. Amaratunga, W. I. Milne, J. Robertson, and P. J. Fallon, J. Non-Cryst. Solids 164, 1111 (1993).

${ }^{36}$ M. A. Tamor and W. C. Vassell, J. Appl. Phys. 76, 3823 (1994).

${ }^{37}$ S. Ulrich, J. Scherer, J. Schwan, I. Barzen, M. Scheib, K. Jung, and H. Ehrhardt (unpublished).

${ }^{38}$ H. Ehrhardt, W. Dworschak, S. Ulrich, K. Jung, M. Scheib, and M. Weiler, New Diamond and Diamondlike Films, edited by P. Vincenzini (Techna Srl, Faenza, Italy, 1995), p. 191. 